Dossiê: Desafios teológicos do Pluralismo Religioso - Artigo original (c) (i)

\title{
Pluralismo, autoridade e legitimação do credo: religiões institucionalizadas e universalistas na encruzilhada dos novos tempos
}

\author{
Pluralism, authority and legitimation of belief: institutionalized and \\ universalist religions on the road of the new times
}

Leno Francisco Danner*

\begin{abstract}
Resumo
Partindo da afirmação de que o pluralismo religioso-cultural está consolidado como o ethos e a base normativa das sociedades contemporâneas, refletirei sobre os desafios por ele postos às instituições religiosoculturais e ao tipo de fundamentação essencialista e naturalizada que elas fomentam individual e socialmente. Meu argumento central consiste em defender que o pluralismo religioso-cultural, que tem um sentido eminentemente positivo e que se enraizou profundamente em nossa vida cotidiana hodierna, leva ao enfraquecimento da autoridade dessas instituições religioso-culturais, minando sua capacidade de monopolizar e de centralizar internamente a si mesmas a legitimação do credo, impondo-o verticalmente aos crentes. Nesse sentido, também defenderei que o pluralismo religioso-cultural não apenas não pode ser ignorado ou minimizado pelas instituições religioso-culturais, mas também pode oferecer uma base normativa importante e inultrapassável para a reformulação e a reestruturação institucionais, no sentido de consolidar, nas instituições religioso-culturais, a moderação discursiva, a abertura democrática aos crentes e aos não-crentes, o enfraquecimento das fundamentações essencialistas e naturalizadas, o acolhimento à alteridade e o refreamento de tendências missionárias e messiânicas que busquem enquadrar, desde fora e sem nenhuma sensibilidade, os contextos religioso-culturais localizados historicamente.
\end{abstract}

Palavras-Chave: Pluralismo; Instituições Religiosas; Autoridade; Legitimação.

\begin{abstract}
Starting from the affirmation of religious-cultural pluralism as consolidated ethos and normative basis of contemporary societies, I will reflect upon the challenges posed by it to religious-cultural institutions and to the type of essentialist and naturalized foundation that they foment individually and socially. My main argument consists of defending that religious-cultural pluralism, which has a totally positive sense and is deeply rooted in our current daily life, weakens the authority of these religious-cultural institutions, undermining their power to monopolize and centralize internally the legitimation of the creed, imposing it vertically to believers and non-believers. I will defend also that religious-cultural pluralism not only cannot be ignored or minimized by religious-cultural institutions, but can offer an important and unsurpassable normative basis to their institutional reformulation and restructuring, in the sense of consolidating, in religious-cultural institutions, discursive moderation, democratic openness to believers and non-believers, weakening of essentialist and naturalized foundations, welcome to otherness, and containment of missionary and messianic tendencies that try to frame, from out and with no sensibility, the religious-cultural contexts historically located.
\end{abstract}

Keywords: Pluralism; Religious Institutions; Authority; Legitimation.

Artigo recebido em 14 de maio de 2015 e aprovado em 24 de novembro de 2015.

* Doutor em Filosofia pela PUC-RS. País de origem: Brasil. E mail: leno_danner@yahoo.com.br

Horizonte, Belo Horizonte, v. 13, n. 40, p. 2009-2035, out./dez. - ISSN 2175-5841 


\section{Considerações iniciais}

A consolidação do pluralismo religioso-cultural e do individualismo dos estilos de vida, que foi possibilitada pelo desenvolvimento da modernidade cultural em sua crítica ao tradicionalismo, é hoje uma realidade claramente perceptível em nossas sociedades democráticas e no âmbito global. O pluralismo religioso-cultural e o individualismo dos estilos de vida, na verdade, são o ponto de partida em termos teórico-práticos, quando se pensa na formulação de fundamentações epistemológico-morais e na construção de projetos societais integrativos, bem como no momento em que se busca a orientação e o repensar das instituições políticas, religioso-culturais e até econômicas. Eles implicam, por fim, na necessidade permanente de se revisar e, se for o caso, de se modificar os paradigmas epistemológico-morais a partir dos quais essas mesmas instituições e todos nós, de um modo mais geral, significamos nossos valores e nossas práticas, com vistas a adequá-los exatamente ao pluralismo e ao individualismo consolidados. Ou seja, são o ponto de partida da formulação de qualquer paradigma epistemológico-moral e de qualquer projeto societal, porque são, em primeiro lugar, o fundamento, o fato de nossa vida cotidiana, que não apenas não pode ser racionalizado ou homogeneizado, senão que, enquanto ethos de nossa vida contemporânea, implica na reformulação e às vezes no enfraquecimento irreversível das fundamentações essencialistas e naturalizadas que ainda são a base das instituições religioso-culturais.

As tensões consistem, portanto, de um lado, no fato de que o pluralismo e o individualismo não aceitam racionalização, dissecação e enquadramento estritos e realizados desde fora, sendo arredios ao universalismo enquanto guarda-chuva normativo dos contextos particulares, bem como no fato de que o individualismo dos estilos de vida objetiva privatizar espaços da vida cotidiana de modo tal que cada indivíduo torne-se o único responsável por suas opções epistemológicomorais e por suas escolhas estético-existenciais, pelo menos em poderosa medida; de outro lado, essas tensões assumem o caráter de reações, por parte das 
instituições religioso-culturais, frente ao avanço avassalador do pluralismo, sob a forma de reafirmação de suas fundamentações essencialistas e naturalizadas e de fortalecimento da autoridade e do poder institucionais no que tange não apenas a monopolizar a legitimação do próprio credo, mas também a orientar a vida dos crentes e dos não-crentes, não obstante o pluralismo religioso-cultural e o individualismo dos estilos de vida. É nessa fronteira tensa que o futuro da evolução sociocultural contemporânea e o futuro das religiões institucionalizadas e universalistas será definido; isto é, o tipo de embate, as forças em jogo e os acordos mútuos, que envolvem renúncias mútuas, principalmente por parte dessas instituições religioso-culturais, determinarão o rumo do pluralismo contemporâneo e os tipos de reformulações institucionais nessas mesmas religiões institucionalizadas e universalistas, necessárias para responder à consolidação do pluralismo religioso-cultural e, com isso, da impossibilidade de um único paradigma epistemológico-moral dar conta de todas essas posições religiosoculturais e de controlar todos os aspectos sociais e individuais decorrentes e afirmadores desse mesmo pluralismo.

Ora, a partir dessa constatação de que o pluralismo religioso-cultural e, com ele, as múltiplas formas de fundamentação epistemológico-morais vieram para ficar, enraizando-se fortemente como ethos sociocultural contemporâneo, pode-se perceber, conforme penso, que a dinâmica normativa, política e evolutiva fundamental de nossas sociedades e do processo de mundialização em curso consiste, em um aspecto poderoso, na tensão entre formas de pensamento e de integração pós-metafísicas e formas de pensamento e de integração metafísicas, tradicionais (outra forma de tensão - que eu não estudarei aqui - diz respeito à contraposição entre modernização e horizontes mítico-tradicionais, que delimita uma mundialização calcada na imposição de uma globalização econômico-cultural euronorcêntrica a todo o mundo). Isto é, a tensão básica de nossa evolução societal surge a partir da contraposição entre o pluralismo religioso-cultural, arredio a qualquer racionalização ou enquadramento normativo por parte de uma posição 
metafísico-teológica ou epistemológico-moral específica, calcada em uma fundamentação essencialista e naturalizada; e as instituições religioso-culturais universalistas, missionárias e messiânicas, cuja base de trabalho é exatamente a afirmação de um tipo de fundamentação essencialista e naturalizada que pretende tanto servir como guarda-chuva normativo de todas as concepções religiosoculturais particulares quanto enquadrá-las desde fora, possibilitando, inclusive, a realização, desde essa concepção essencialista e naturalizada, de um projeto societal de alcance cosmopolita.

Ora, diante da situação de consolidado pluralismo religioso-cultural e individualismo dos estilos de vida, como fica a autoridade das instituições religioso-culturais tradicionais? É possível a estas instituições manterem a legitimação exclusiva do credo? É possível que elas possam assumir a tarefa de fundamentar e de controlar todos os aspectos das vidas dos crentes e dos nãocrentes? Por outro lado, como essas mesmas instituições religioso-culturais devem encarar o pluralismo? E, por fim, até onde o pluralismo religioso-cultural e o individualismo dos estilos de vida podem ir, em seu enfrentamento das instituições religioso-culturais universalistas? O que aqueles podem exigir destas? Meu argumento geral, a ser defendido nas próximas linhas, consiste em que o pluralismo religioso-cultural e o individualismo dos estilos de vida possuem um sentido eminentemente positivo, democratizante e moralmente inclusivo, pondo por terra toda e qualquer violência contra as diferenças, tornando essa violência contra as diferenças algo inaceitável. Ora, com isso, ao consolidar-se como a base de nossa vida atual e sendo eminentemente não-racionalizável e nãohomogeneizável desde outra posição religioso-cultural ou epistemológico-moral, esse mesmo pluralismo religioso-cultural implicará em reformulações nas instituições de um modo geral (incluindo aqui as instituições políticas) e nas instituições religioso-culturais em particular, exigindo moderação discursiva, abandono ou arrefecimento da fundamentação essencialista e naturalizada, limitação da função missionária e messiânica, democratização do processo de legitimação do credo, o que não significa, por outro lado, o fim das instituições 
religioso-culturais e de seu papel de guias de uma determinada comunidade de crentes.

\section{1 fato do pluralismo e a questão da fundamentação}

Vivemos em uma época de pluralismo escancarado e, pode-se dizer com orgulho, consolidado, pelo menos enquanto ethos sociocultural e normativo de nossos tempos. Ainda falta, é verdade, um longo caminho em termos de arranjo institucional e de reformulação dos códigos e dos valores essencialistas e naturalizados, presentes nas mais variadas instituições (políticas, religiosas, culturais, econômicas etc.), para que o pluralismo esteja solidamente institucionalizado e seja a base normativa a partir da qual todos os códigos, valores e práticas são fundados e dinamizados ao longo do tempo. Entretanto, ele chegou para ficar, seja no que diz respeito à constituição de nossas sociedades democráticas, seja no que se refere ao horizonte global de um modo mais amplo (RAWLS, 2000, 2002, 2003; HABERMAS, 1990, 2002). Em um e em outro caso, é possível perceber-se e viver-se - para não dizer defrontar-se ou até chocar-se com a pluralidade heterogênea das visões de mundo, das concepções epistemológico-morais, religioso-culturais e político-econômicas. Note-se o primeiro aspecto-chave do pluralismo religioso-cultural consolidado: sua heterogeneidade radical.

Heterogeneidade significa a existência de múltiplas posições epistemológicomorais para os mesmos problemas; isto é, cada posição epistemológico-moral ou religioso-cultural significa de um modo totalmente particular e autorreferencial a sua compreensão sobre qualquer aspecto da vida cotidiana, sendo um mero acaso que uma e outra posição epistemológico-moral ou religioso-cultural tenham algo em comum. Repito: toda e qualquer posição epistemológico-moral ou religiosocultural tem uma forma própria e interna de significação e de fundamentação de sua visão de mundo, de seus valores e de suas práticas. São posições 
epistemológico-morais ou religioso-culturais que representam verdadeiras formas de vida auto-subsistentes, sem qualquer identidade externa, sem qualquer transliteração desde outro contexto - ou que, de todo modo, querem enfatizar exatamente a autorreferencialidade de seu modo de vida e, aqui, a centralidade do seu tipo de fundamentação no que tange a garantir a validade dos seus códigos e de suas práticas.

Note-se, com isso, o segundo aspecto fundamental dessa situação contemporânea de pluralismo epistemológico-moral e religioso-cultural: a heterogeneidade não pode ser homogeneizada e nem reduzida a um denominador comum, particularmente se esse valor comum pertencer a alguma posição epistemológico-moral ou religioso-cultural específica (e ele sempre pertence a uma posição epistemológico-moral ou religioso-cultural). Simplesmente não existe um denominador comum que possa servir como guarda-chuva normativo ou poder institucional capaz de abarcar as concepções epistemológico-morais ou religiosoculturais particulares, capazes de dissecá-las desde fora, de racionalizá-las desde fora, violando sua lógica autorreferencial e auto-subsistente de fundamentação. Não há acordo quanto a um fundamento comum e nunca haverá, principalmente pelo fato de que nenhuma concepção epistemológico-moral ou religioso-cultural abre mão de seus princípios internos, do caráter totalmente particular de sua forma de vida e de seus processos de fundamentação frente às demais posições epistemológico-morais ou religioso-culturais.

Não existe um denominador comum e nem um princípio normativo garantidor, seja da homogeneização desse pluralismo radical absolutamente heterogêneo, seja da organização desse pluralismo radical sob um mesmo guardachuva normativo, que pudesse garantir - desde fora ou de cima para baixo - a crítica e a integração, ajuizando epistemologicamente e enquadrando praticamente cada contexto simbólico particular de acordo com as regras que constituem aquele guarda-chuva normativo sobreposto às posições epistemológico-morais ou religioso-culturais contextuais. O universal, aspiração central da filosofia e da 
teologia ocidentais, não apenas foi destronado deste posto de guarda-chuva normativo dos horizontes simbólicos particulares, localizados históricoculturalmente (inclusive porque, tradicionalmente, esteve associado ou ao Cristianismo, ou à cultura europeia moderna, ou mesmo ao paradigma técnicocientífico - isto é, a posições epistemológico-morais específicas, também contextuais), senão que também foi tornado obsoleto ou incapaz de homogeneização diante desta autorreferencialidade de cada posição epistemológico-moral e religioso-cultural frente a si mesma e frente às demais posições.

Aparece, então, o terceiro aspecto teórico-normativo de nossos tempos de consolidado e radicalizado pluralismo: o relativismo epistemológico-moral; isto é, falando de modo mais específico, a incapacidade de uma única posição epistemológico-moral ou religioso-cultural em fundamentar de modo essencialista ou naturalizado, absoluto ou universal, todos os códigos e todas as práticas de todos os horizontes culturais, localizados historicamente e sempre singulares. Relativismo epistemológico-moral não deve ser entendido - que fique bem claro como uma ausência de fundamentação objetiva dos valores, mas sim, conforme dito acima, como a impossibilidade e a incapacidade de uma única posição epistemológico-moral ou religioso-cultural em sustentar e abarcar todos os contextos simbólicos particulares, fundamentando valores universalistas e servindo como denominador comum para a crítica e a integração de todos esses mesmos contextos culturais historicamente localizados - isso tanto dentro de uma sociedade democrática quanto no contexto mundial em geral. Relativismo epistemológico-moral é a celebração da heterogeneidade irredutível e absolutamente plural, das múltiplas formas de vida e de significação.

Há uma contraposição bem clara, aqui, entre o relativismo epistemológicomoral e a noção clássica de universalismo epistemológico-moral legada pela tradição filosófica grega e consolidada pela reformulação dessa mesma tradição 
filosófica por parte da teologia cristã medieval, conceito esse que foi apropriado, depois, pela filosofia moderna como sua base normativa e associado à própria modernidade europeia enquanto ethos universal, podendo servir tanto como paradigma epistemológico-moral para a crítica quanto como projeto societal para a integração - isto é, no caso da Europa moderna, como bojo normativo para a fundamentação dos valores e das práticas e para a homogeneização e condução de todas as culturas particulares (o que explica, por exemplo, a naturalidade da colonização dos contextos americanos e africanos por parte das nações europeias, considerados como não possuindo história). Essa contraposição entre relativismo e universalismo, com a consequente vitória, hodiernamente, desse mesmo relativismo epistemológico-moral, desfaz uma significação desde longa data nefasta de relativismo (e, consequentemente, de pluralismo) e, por outro lado, desconstrói uma concepção positiva que desde longa data tem marcado o sentido do universalismo.

Dito de outro modo, tradicionalmente, o relativismo e o pluralismo foram entendidos com um mal, posto que impediam o universalismo, ao passo que o universalismo epistemológico-moral, tradicionalmente, foi entendido como algo bom, posto que, por servir como guarda-chuva normativo dos contextos culturais particulares, historicamente localizados, seria sua condição de validade ou não, sua base normativa, capaz de enquadrá-los teórica e praticamente. A crítica e a integração, ainda na tradição filosófico-teológica ocidental, apropriada depois pela filosofia moderna desenvolvida na Europa, somente seriam possíveis por causa do - e com base no - universalismo epistemológico-moral, que, por servir de guardachuva normativo dos contextos particulares, teria a capacidade de crítica teórica e de enquadramento prático deles. Nesse sentido, na dinâmica de fundamentação dessa tradição filosófico-teológica ocidental, somente haveria verdade e moralidade, ou sentido em geral, no universalismo e a partir dele, ao passo que o relativismo conduziria ao ceticismo, ao vale-tudo moral, à degeneração pura e simples. Obviamente, daqui (isto é, da tradição filosófico-teológica ocidental, assumida pela modernidade europeia) vem, como o estou dizendo, a concepção 
negativa geralmente associada ao relativismo, ao contextualismo e ao pluralismo, bem como a correlata concepção positiva associada ao universalismo epistemológico-moral.

Ora, nessa concepção tradicional de fundamentação, desenvolvida pela filosofia grega em Platão e Aristóteles, remodelada pela teologia cristã de Santo Agostinho e Santo Tomás de Aquino, e assumida na filosofia moderna por Immanuel Kant e G. W. F. Hegel, o particular ou contextual está sempre submetido ao - e dependente do - universal, que é a verdade, o sentido e a base daquele; o pluralismo epistemológico-moral ou religioso-cultural necessita de um guardachuva normativo ou de um denominador comum universalista que permita a crítica e o enquadramento daquele mesmo pluralismo, sua integração e condução ao longo do tempo. A ideia de que a verdade e a moralidade necessitam ter validade e alcance universais, estando situadas para além dos contextos histórico-culturais particulares, de modo a abarcá-los ao estilo de um guarda-chuva normativo, bem como a ideia de que verdade e moralidade, sempre universais, são destruídas pelo contextualismo extremado (na medida em que se o afirma como a base de qualquer sentido e de qualquer fundamentação), definiram, no desenvolvimento da civilização ocidental (enquanto síntese da sociedade greco-latina, do Cristianismo medieval e da Europa moderna - filosofia, teologia e ciência), o tipo de paradigma epistemológico-moral, de projeto societal integrativo e de relação com o tradicional que, efetivamente, colocou o universalismo em especial e a modernidade de um modo geral, entendidos como a verdade do contextualismo e sempre contrapostos ao relativismo e ao particularismo, enquanto a base de justificação de uma prossecução totalizante da modernização ocidental, que é altamente assimilacionista e deslegitimadora dos contextos simbólicos particulares, e que continua se concebendo e se afirmando como universalista, como universalismo (LYOTARD, 1999). 
Essa é a mesma base das religiões institucionalizadas e universalistas, de caráter missionário e messiânico, que estão calcadas em uma fundamentação essencialista e naturalizada no que tange à orientação interna frente aos próprios crentes e mesmo na relação com os não-crentes de todos os contextos (RORTY, 2010; VATTIMO, 2004)․ Nas religiões institucionalizadas e universalistas, essa fundamentação essencialista e naturalizada parte do fato de que uma objetividade forte ou universalista é a condição da fundamentação epistemológico-moral e da própria integração prática de cada contexto e, em última instância, de todos os contextos (COLLINS, 2006). Em um poderoso aspecto, portanto, nas religiões institucionalizadas e universalistas, com seu tipo de fundamentação essencialista e naturalizada, afirma-se a crença de que um contexto particular não é capaz de fundamentar seus próprios valores e, em última instância, de que o subjetivismo e o relativismo, derivados da afirmação dos contextos histórico-culturais particulares como a única fonte de sentido no que tange à fundamentação epistemológico-moral e à orientação prática, não apenas não possibilitam sentido e orientação, verdade e moralidade em sentido objetivo, senão que conduzem ao ceticismo, ao vale-tudo moral - isto é, subjetivismo e relativismo são um mal, o que também significa que o pluralismo, se não necessariamente é um mal, ainda assim não é algo totalmente bom, é algo deficitário, parcial. Em vários aspectos, portanto, pode-se entender por que o pluralismo, com suas consequências em termos de subjetivismo e relativismo, é percebido como um problema para as fundamentações essencialistas ou naturalizadas assumidas pelas instituições religioso-culturais de caráter universalista, missionário e messiânico. Aliás, essa vocação missionária - de pregar a luz da verdade, a salvação a todo o globo, de conceber a humanidade como uma grande família - e messiânica - de levar essa luz da verdade e da salvação a toda a humanidade, tornando-a uma família homogênea - somente faz sentido no momento em que se entende que é justamente uma fundamentação essencialista e naturalizada, fortemente universalista, que é colocada como paradigma

\footnotetext{
${ }^{1}$ Esse tipo de fundamentação essencialista e naturalizada aparece claramente nas constituições e nos decretos do Concílio Vaticano II. A respeito disso, pode-se conferir: Constituição Dogmática "Lumen Gentium", § 01, p. 39, § 4, p. 41; Constituição Pastoral "Gaudium et Spes", § 201, p. 144.
} 
epistemológico-moral e projeto societal capaz de servir como guarda-chuva normativo para a crítica, o enquadramento e a integração de todos os contextos particulares, percebidos, em algum poderoso aspecto, como inferiores àquela posição religioso-cultural universalista e naturalizada, fortemente universalista.

Entretanto, as condições contemporâneas em termos de democracia, de secularização, de pluralismo e de individualismo imprimem uma mudança radical nesse tipo de fundamentação filosófico-teológica tradicional, que pressupunha o universalismo como verdade e condição de sentido do particularismo e do contextualismo; que pressupunha que a crítica e a integração somente seriam possíveis por meio de noções essencialistas ou naturalizadas - fortemente objetivas - de verdade e de moralidade, isto é, por meio do universalismo; e que pressupunha, por fim, que o contextualismo, o relativismo, o subjetivismo e, em última instância, o pluralismo eram parciais, problemáticos, às vezes um mal no que diz respeito à fundamentação epistemológico-moral objetiva ou universal. Também caiu por terra, em grande medida, a consequência daqui diretamente adveniente, a saber, a necessidade de homogeneização como condição da integração e do sentido do pluralismo, da heterogeneidade - heterogeneidade que se apresenta, portanto, como não-racionalizável, não-homogeneizável, como indomável, por assim dizer, a partir de uma posição essencialista, naturalizada ou universalista. Hoje, o particular, que é sempre singular, venceu, e derrubou aquela clássica relação de superioridade do universal em relação a ele, assim como deslegitimou aquela necessidade imperiosa de que tivéssemos um paradigma epistemológico-moral uniforme e fortemente objetivo como condição do sentido e da fundamentação. Hoje, o particular sempre dá a última palavra, o que não pode ser considerado ruim ou desconcertante.

A consolidação do pluralismo religioso-cultural e do individualismo dos estilos de vida - e aqui teríamos o quarto aspecto da vida contemporânea - leva diretamente ao enfraquecimento das fundamentações metafísico-teológicas, ou 
essencialistas e naturalizadas, que passam a ter de conviver, agora, com formas de fundamentação e práticas epistemológico-morais diferentes e às vezes antagônicas. O pluralismo instaura essa Torre de Babel em termos de fundamentação epistemológico-moral e mesmo de formulação de um projeto societal integrativo de abrangência cosmopolita ou universal, pretensamente homogeneizador das diferenças. Na verdade, o pluralismo é até mais radical do que isso, posto que não apenas instaura essa contraposição entre formas de fundamentação e de integração pós-metafísicas e formas de fundamentação e de integração metafísicas ou tradicionais, senão que implica na assunção de uma anarquia em termos de fundamentação e em uma negação no que tange à possibilidade de homogeneização, a partir de um denominador comum, entre as múltiplas formas de vida e de fundamentação - e cada forma de vida é uma forma singular de fundamentação, não há separação entre vida e fundamentação. O pluralismo é anárquico neste aspecto de não aceitar nem racionalização e homogeneização estritas das formas de vida, que são sempre singulares e autorreferenciais, e nem, como consequência, uma assunção de um paradigma epistemológico-moral universalista que pudesse, sobreposto às posições religioso-culturais particulares, enquadrá-las desde fora e de cima para baixo (DANNER, 2014).

Daqui surge a dupla tensão básica da evolução de nossas sociedades e do progressivo entrelaçamento mundial que a globalização econômico-cultural conduzida desde o horizonte euro-americano levou e leva a efeito hodiernamente. Essa tensão, portanto, diz respeito, em um aspecto, à contraposição entre o pluralismo religioso-cultural e epistemológico-moral, de um lado, e, de outro, às instituições religioso-culturais universalistas, missionárias e messiânicas (como as grandes religiões mundiais). E essa tensão apresenta, em segundo lugar, o sentido de contraposição entre a modernização econômico-cultural e os horizontes vitais tradicionais, não-modernos. A modernização econômico-cultural está calcada na racionalização incessante de todos os aspectos da vida humana e de tendência totalizante, que dinamiza e legitima a ciência e a técnica e o próprio capitalismo enquanto, respectivamente, valores epistemológicos e materiais universalistas. Ela 
é assumida pelo - e de todo modo se confunde com o - horizonte euronorcêntrico, que a coloca como paradigma epistemológico-moral universalista e projeto societal cosmopolita, como a forma por excelência de crítica, de enquadramento e de integração global. E os horizontes tradicionais, em contrapartida, são atacados de maneira incessante, normativa e praticamente, por esse tipo de modernização econômico-cultural, que os está destruindo pouco a pouco (DUSSEL, 1993, 2000; TODOROV, 1993). De todo modo, aqui, concentrar-me-ei apenas naquele primeiro aspecto da evolução sociocultural contemporânea, a saber, a tensão entre o pluralismo e as instituições religioso-culturais universalistas.

O tipo de problema que surge daqui consiste no fato de que o pluralismo é, por excelência, não-homogeneizável e não-racionalizável, isto é, como disse acima, negador ou anárquico em relação às fundamentações essencialistas e naturalizadas; as concepções metafísicas (e as instituições religioso-culturais se enquadram nessa categoria), por outro lado, são fundamentações essencialistas e naturalizadas que objetivam controlar todos os aspectos da vida social e individual, bem como oferecer um paradigma epistemológico-moral fortemente objetivo e, geralmente, contraposto ao pluralismo, ao subjetivismo e ao relativismo - as fundamentações essencialistas e naturalizadas acreditam oferecer essa base normativa para a homogeneização da heterogeneidade, para a organização da pluralidade, interrompendo, por conseguinte, o subjetivismo, o relativismo e o ceticismo. Ora, essa tensão entre pluralismo e fundamentações essencialistas e naturalizadas gera possíveis tensões institucionais, políticas, culturais e epistemológicas, devido ao fato de que não são apenas questões teóricas, mas sim, antes de tudo, formas de vida e de significação individual e coletiva. Nós vivemos nossas fundamentações, nossa forma de vida é uma forma de fundamentação. Logo, se como vivemos, fundamentamos, então não conseguiremos ou dificilmente conseguiremos uma homogeneização estrita entre formas de vida radicalmente diferentes, bem como não conseguiremos impor coletivamente, de modo vinculante, uma forma de vida e de fundamentação entre essas formas de vida plurais. Toda vez que essa 
racionalização e essa homogeneização são tentadas institucionalmente, praticamente, politicamente, epistemologicamente, a negação e a violência contra as diferenças surgem como consequências diretas.

O pluralismo e o individualismo carregam e consolidam uma situação básica da realidade contemporânea: certas coisas são somente relativas à cada forma de vida e ao tipo de fundamentação representada por ela; outras tantas coisas são apenas questão de escolha pessoal, relativas ao tipo de orientação existencial que cada indivíduo dá à sua própria vida. Isso, evidentemente, contrasta e se contrapõe, ainda que nem sempre de modo radical, conforme penso, com as fundamentações essencialistas e naturalizadas defendidas pelas instituições religioso-culturais, levando a possíveis tensões. Ora, tais tensões seriam evitadas por meio de uma das duas opções seguintes: ou uma moderação em termos da intensidade e do alcance das fundamentações essencialistas e naturalizadas, que já não podem mais assumir uma pretensão universalista para além e deslegitimadora do pluralismo e que também busque controlar todos os aspectos da vida individual e da dinâmica social; ou uma ausência ou mesmo cessação dessas mesmas fundamentações essencialistas e naturalizadas sobre campos específicos da vida individual e social. O certo é que essas fundamentações essencialistas e naturalizadas são impactadas na sua pretensão de objetividade forte, integradora, guardadora e salvífica dos contextos singulares e das vidas particulares, de modo que a autoridade das instituições religioso-culturais, calcada naquelas fundamentações essencialistas e naturalizadas, encontra dificuldade tanto de afirmar-se indistintamente quanto de impor genericamente valores e práticas. Os novos tempos de pluralismo e de subjetivismo, portanto, representam um grande desafio às religiões institucionalizadas e universalistas em sua pretensão de construir e de fomentar uma fundamentação essencialista e naturalizada. 


\section{Desafios teológicos do pluralismo religioso}

Ora, que tipo de impacto e de desafio teológico o pluralismo religiosocultural imprime às instituições religioso-culturais? O impacto diz respeito exatamente à fundamentação institucional do credo e ao tipo de vinculação social que as instituições religioso-culturais mantêm frente aos crentes, aos não-crentes e às outras instituições religioso-culturais. Como consequência, o tipo de desafio teológico que o pluralismo coloca às instituições religiosas consiste, especificamente, na reformulação institucional e no enfraquecimento das fundamentações essencialistas e naturalizadas que são formuladas e fomentadas desde a instituição religioso-cultural que é guardadora do credo. No caso do impacto em relação à fundamentação institucional do credo e à vinculação social das instituições religioso-culturais, pode-se perceber que, com os consolidados pluralismo religioso-cultural e individualismo dos estilos de vida (ou direitos individuais), as instituições religioso-culturais veem-se, em sua atividade missionária e messiânica, diante de uma barreira que elas já não podem mais ultrapassar; isto é, com a consolidação de diferenças religioso-culturais irreconciliáveis e não-homogeneizáveis acerca do sentido da vida (individual e coletiva), que é o verdadeiro significado do pluralismo, tem-se o fim de uma tarefa de fundamentação e de missionarização do credo que poderiam ser feitas sem qualquer refreamento ou consideração das próprias diferenças, das próprias escolhas individuais e do próprio pluralismo. No caso do desafio teológico colocado pelo pluralismo, ou seja, da reestruturação institucional e do enfraquecimento das fundamentações essencialistas e naturalizadas, trata-se de uma exigência basilar colocada pelo próprio pluralismo e que é condição da própria viabilidade de uma evolução sociocultural minimamente estável e democrática. Por outras palavras, não se pode mais passar ao largo do pluralismo e nem lutar contra ele.

Note-se que não é apenas a separação entre religião e política que está no cerne do problema colocado pelo pluralismo em seu questionamento e 
enquadramento das instituições religioso-culturais; é também o próprio limite de atuação das religiões institucionalizadas, o próprio limite da vinculação sociocultural das instituições religioso-culturais, limite esse que deve ser redesenhado por causa do pluralismo e do individualismo dos estilos de vida. $\mathrm{O}$ pluralismo religioso-cultural, desse modo, não apenas problematiza e retoma, insistentemente, a separação entre religião e política, entre instituições religiosas e instituições públicas, reafirmando a secularização e o laicismo como as bases da democracia, senão que questiona o próprio espaço privado-público que resta às instituições religioso-culturais em termos de fundamentação e de fomento do credo que elas guardam (MARRAMAO, 1997; CATROGA, 2006; HABERMAS, 2012). Dito de outro modo, a separação entre religião e política não resolve todos os problemas de violação à integridade das diferenças e nem põe um fim às fundamentações essencialistas e naturalizadas que, dinamizadas desde as instituições religioso-culturais, buscam, tanto no círculo dos crentes quanto mais além, em termos de esfera pública, contraporem-se ao pluralismo religioso-cultural e ao individualismo dos estilos de vida.

O que isso significa? Significa que, não obstante a separação entre política e religião, é possível que, desde dentro da comunidade dos crentes, as instituições religioso-culturais possam fundar e fomentar fundamentações essencialistas e naturalizadas que possam questionar a legitimidade e a viabilidade do pluralismo e do individualismo. Pode-se muito bem, neste caso, respeitar minimamente aquela separação entre política e religião, mas, por outro lado, dentro da própria comunidade de crentes ou da própria instituição religioso-cultural, negar direitos iguais às mulheres, deslegitimar a homossexualidade, formas outras de família e de religião e de cultura que não os modelos tradicionais, etc. Com isso, não apenas a diferença entre religião e política cai por terra, como a religião retoma a vinculação social que sempre teve e nunca abandonou, na medida em que a política é algo mais amplo do que apenas a política representativo-partidária. Ora, se a política diz respeito à vida cotidiana, à democracia, ao reconhecimento, à solidariedade, à igualdade e à liberdade que temos e que vivemos no dia a dia, não apenas com 
nossos irmãos e nossas irmãs de credo, mas com a pluralidade irreconciliável $e$ não-homogeneizável de indivíduos e de grupos, então é óbvio que as fundamentações essencialistas e naturalizadas, ao fundarem e afirmarem modelos epistemológico-morais tradicionais, retomam uma intersecção entre política e religião que está calcada nessas fundamentações essencialistas e naturalizadas, ou seja, em fundamentações homogeneizadoras, em grande medida segregacionistas e contrapostas às diferenças irredutíveis - o tradicional, enquanto afirmado como modelo hegemônico e homogeneizador por excelência, desde dentro das instituições para fora delas ataca e deslegitima o pluralismo e tudo o que cai fora daquela concepção tradicional.

Por isso, o maior desafio do pluralismo religioso-cultural e do individualismo dos estilos de vida consiste em exigirem das instituições religiosoculturais mais do que a simples e, às vezes, ineficaz separação entre religião e política. O desafio que o pluralismo e o individualismo lançam consiste em que as instituições religioso-culturais possam renovar desde dentro suas estruturas de poder, o tipo de fundamentação e de autoridade que dinamizam frente aos crentes e aos não-crentes. Pois aqui está o verdadeiro fundamento da vinculação social e da função socializadora das instituições religioso-culturais. É desde dentro de sua comunidade de crença e de fé que a dinâmica de formação de comportamentos, práticas e valores espraia-se para a sociedade como um todo, definindo configurações sociais, formas culturais e valores coletivos que acabam sendo fundamentais para se entender a evolução social. Ora, se o verdadeiro enigma de uma evolução social democrática, inclusiva e pacífica depende da configuração interna das instituições religioso-culturais, como acredito, então é somente no momento em que o pluralismo for colocado por essas mesmas instituições como a base normativa para a sua reformulação interna e para o repensar de sua atuação social que, efetivamente, a religião reconciliar-se-á com a política, isto é, com uma forma de vida sociocultural solidária, igualitária, libertária, democrática. Nessa situação, não apenas a separação entre política e religião não será exigida como 
fundamento da democracia, senão que as instituições religioso-culturais tornar-seão baluartes da própria democracia, protegendo-a contra toda e qualquer forma de injustiça.

Nesse sentido, o grande desafio teológico da contemporaneidade, colocado pelo pluralismo religioso-cultural e mesmo pelo individualismo dos estilos de vida, consiste em que eles - pluralismo e individualismo - sejam colocados como a base normativa a partir da qual as instituições religioso-culturais reformulam e modificam desde dentro suas estruturas e fundamentações essencialistas e naturalizadas. É o tipo de autoridade institucional verticalizada, monopolizada pelas instituições religioso-culturais, e a forma de fundamentação essencialista e naturalizada encampada por essas mesmas instituições que precisam ser minimizadas por causa do pluralismo e como condição de se o respeitar e promover ao longo do tempo. O pluralismo religioso-cultural e o individualismo dos estilos de vida não podem ser apenas um freio à atuação social das religiões, como se eles impusessem uma perda às religiões, e percebidos como negativos por essas mesmas religiões, mas também e, sobretudo, devem ser o conteúdo normativo a partir do qual essas mesmas instituições religiosas reformulam suas fundamentações essencialistas e naturalizadas de modo a sorver o caldo normativo libertador que somente as diferenças irredutíveis, irreconciliáveis e nãohomogeneizáveis, em toda a sua riqueza normativo-cultural e beleza estética, possuem e podem dar. O pluralismo religioso-cultural não precisa ser visto como obstáculo, como inimigo e mesmo como gerador da perda de importância das instituições religioso-culturais; o pluralismo é uma fonte de vida nova - utilizando uma metáfora bíblica -, na medida em que possibilita a correção daquele tipo totalizante, homogeneizador e segregador de fundamentação essencialista e naturalizada, que procura a todo custo assimilar, racionalizar e reduzir todas as diferenças a partir de um denominador comum, deslegitimando tudo aquilo que não se enquadra nessa fundamentação essencialista e naturalizada. 
Mas, em vários aspectos, o pluralismo é visto em um sentido negativo que não faz jus nem à sua riqueza sociocultural e nem à sua importância normativa para a renovação e correção das instituições religioso-culturais. Com efeito, é surpreendente que a $11^{\mathrm{a}}$ Assembleia Geral dos Bispos - o assim chamado "Sínodo da Família" - tenha por base duas afirmações que estão diretamente em contraposição ao individualismo e ao pluralismo. Com efeito, fala-se, no texto prévio resultante desse encontro, ocorrido em outubro de 2014, do "grande perigo" representado "pelo individualismo exasperado", que, "percebido como absoluto", “distorce o significado da família” (§ 1, 9), ao mesmo tempo em que se afirma que certos contextos religioso-culturais particulares põem em perigo a integridade da família (tradicional) ( $\S 7$ ). No que diz respeito aos contextos religioso-culturais particulares, não-cristãos, o texto afirma, ainda, que, desde o Concílio Vaticano II, são reconhecidos elementos positivos presentes neles, "não obstante seus limites e insuficiências" (§ 19)². A pergunta é: quais as limitações e insuficiências dos contextos religioso-culturais particulares, isto é, do pluralismo religioso-cultural? E por que o individualismo aparece novamente como negativo, como um perigo? Por fim, qual a necessidade de colocar-se a família tradicional (mas tradicional em qual contexto?) como o modelo de família cristã ( $§ 11$ )? Note-se, novamente, que meu objetivo não consiste em deslegitimar o tipo de fundamentação teológica próprio à Igreja Católica e sua versão do Cristianismo, ou o tipo de fundamentação essencialista e naturalizada, metafísico-teológica, que caracteriza as instituições religioso-culturais universalistas; é, sim, questionar o porquê de esse tipo de fundamentação apresentar uma totalização e unidimensionalização tão exacerbadas, implicando em confronto direto com o pluralismo e o individualismo, bem como em minimização da importância do pluralismo e do individualismo, ou mesmo em sua deslegitimação3.

\footnotetext{
${ }^{2}$ http://press.vatican.va/content/salastampa/en/bollettino/pubblico/2014/10/13/0751/03037.html

${ }^{3}$ Isso também pode ser percebido em várias passagens de constituições e decretos oriundos do Concílio Vaticano II. Por exemplo, na Declaração Nostra Aetate, acerca das religiões não-cristãs, $\S \S 1.578$ e 1579, p. 619-620; e no Decreto "Unitatis Redintegratio", $\S \S 752$, 763, 764 e 767, p. 310-315.
} 
Nesse sentido, penso que os novos tempos de pluralismo religioso-cultural e de individualismo dos estilos de vida, enquanto fatos epistemológicos, normativos e políticos consolidados do - e no - mundo contemporâneo, implicam que as instituições religioso-culturais adequem-se a eles; isso de um modo tal que passem para primeiro plano os seguintes aspectos metodológico-normativos os quais, enquanto base programática de uma reestruturação desde dentro dessas mesmas instituições, teriam como consequência a moderação discursiva, a abertura democrática, o relaxamento dos controles sobre gênero e sexualidade, o enfraquecimento das fundamentações essencialistas e naturalizadas e o refreamento da tendência missionária e messiânica, de modo a promover-se o pluralismo e o individualismo dos estilos de vida (e tê-los por fundamento normativo, como já falei acima) e a proteger-se e fomentar-se a integridade da alteridade, a qual nunca poderá ser homogeneizada, racionalizada e subsumida em e por uma concepção essencialista e naturalizada ou racionalista e universalista.

Duas tarefas surgem daqui. A primeira delas consiste no enfraquecimento das fundamentações essencialistas e naturalizadas que marcam a compreensão e a legitimação do credo pelas instituições religioso-culturais. Com efeito, como procurei mostrar ao longo do texto, o pluralismo religioso-cultural e o individualismo dos estilos de vida não apenas não podem ser racionalizados ou englobados por qualquer guarda-chuva normativo oferecido pelas posições epistemológico-morais de aspiração universalista, como também, na medida em que as fundamentações essencialistas assumem - e elas sempre assumem - a forma de um paradigma normativo garantidor da crítica, do enquadramento e da integração, bem como um viés político que organiza as instituições públicas e orientam seu trabalho socializador e sua vinculação social, as diferenças correm sério perigo de ser deslegitimadas ou minimizadas em sua importância, inclusive violadas em sua autorreferencialidade. Da mesma forma, em relação a esta primeira tarefa, a autoridade da instituição religioso-cultural em monopolizar internamente à instituição e por meio de sua elite eclesiástica a legitimação do credo e sua aplicação poderia ser enfraquecida, abrindo-se espaço para que crentes 
e mesmo não-crentes fossem chamados a discutir, junto com aquelas elites eclesiásticas, o modo como o credo pode ser interpretado e vivido, inclusive buscando-se ouvir crentes e não-crentes em relação a como eles gostariam de significar partes específicas do próprio credo (como, por exemplo, gênero e sexualidade, o fato de as autoridades eclesiásticas serem basicamente homens, etc.).

Com isso, e essa seria a segunda tarefa, a reformulação ou até o abandono de partes do credo, para não se dizer de um processo de fundamentação essencialista e naturalizada enquanto projeto e monopólio das instituições religioso-culturais, é uma consequência (e até uma exigência) da consolidação do pluralismo religiosocultural e do individualismo dos estilos de vida e, com isso, da afirmação da irredutibilidade das diferenças umas em relação às outras. Reformular ou até abandonar certas partes do credo - pense-se nas questões de gênero e de sexualidade e no tipo de tratamento negativo dado às diferenças - é o caminho por excelência, conforme penso, para se combater formas de discriminação e de violação da integridade das diferenças, na medida em que muitas dessas formas de discriminação encontram seu fundamento no fato de que grupos religioso-culturais específicos interpretam a seu modo o credo como um todo ou passagens específicas dos textos religiosos (e muitas vezes contando com a complacência das instituições religioso-culturais e de suas autoridades eclesiásticas), enfatizando que o credo como um todo ou tais passagens seletivas têm, efetivamente, esse cunho de condenação e de deslegitimação das diferenças. Ora, no momento em que essas fundamentações epistemológico-morais controversas (novamente: gênero e sexualidade, bem como o tipo de percepção em relação às diferenças presente nas posições essencialistas e naturalizadas, de que já falei na primeira seção deste texto) são reformuladas ou abolidas dos textos religiosos, e na medida em que as instituições religioso-culturais assumem uma postura clara e aberta de afirmação do pluralismo e do individualismo, bem como de combate às formas de violação e de discriminação das diferenças, todos os problemas ligados às concepções 
essencialistas e naturalizadas (negação ou minimização da importância das diferenças) terminam e os grupos fascistas nelas baseados perdem sua legitimidade para utilizarem-se do credo e dos textos religiosos para atacar e deslegitimar as diferenças.

No documento resultante da $11^{\mathrm{a}}$ Assembléia Geral dos Bispos (o Sínodo da Família), parte-se da afirmação de que nosso tempo apresenta problemas graves aos quais a instituição religioso-cultural, afirmando seu tipo de fundamentação essencialista e naturalizada calcada na Bíblia, pode resolver ou servir como plataforma normativa para tal resolução. Inclusive, procurei trazer passagens daquele documento que efetivamente consideram o pluralismo e o individualismo com menos importância e valor do que eles efetivamente possuem, ao contrário da grande valorização do credo cristão (valor totalmente justificado, é claro). Ora, o nosso tempo possui certamente muitos problemas, o mais grave deles calcado em um modelo de colonização econômico-cultural promovido desde o horizonte euroamericano, que causa pobreza, desigualdade, violência, destruição das diferenças, etc.4. Mas o problema do nosso tempo com certeza não consiste no pluralismo religioso-cultural e no individualismo dos estilos de vida - e minimizar a importância deles ou percebê-los como empecilhos para a resolução de nossos problemas não representa nem o ponto de partida e nem a estratégica metodológica, normativa, epistemológica e política adequadas. $\mathrm{Na}$ verdade, o problema não é a degeneração do nosso tempo, nem é o nosso tempo que está em crise; o que está em crise são as instituições de um modo geral e as instituições religioso-culturais em particular, na medida em que o pluralismo religioso-cultural

\footnotetext{
${ }^{4}$ De fato, no discurso da modernização econômico-cultural são exatamente os fundamentalismos religiosos que geram desestabilização política e marginalização social, de modo que, aqui, essa mesma modernização econômico-cultural assumiria uma função messiânica em relação a eles - veja-se, em relação a isso, a guerra contra o terror como tendo por base a defesa da civilização contra a barbárie, da democracia contra o fundamentalismo, dos direitos contra o dogmatismo, da razão contra o fanatismo. Embora não seja o tema central neste texto, insisto nele devido ao fato de que, em minha percepção, não são os fundamentalismos religiosos que se constituem no cerne de nossos grandes problemas mundiais, como a fome, a guerra, a degradação ecológica, etc., e sim a própria modernização cultural-econômica. Inclusive, em relação a isso, acredito que a renovação das instituições religiosas universalistas e sua aproximação permite um enfrentamento mais consistente deste movimento totalizante constituído pela colonização cultural-econômica capitalista. A encíclica papal Laudatio Si, de Francisco, que trata tanto da ecologia quanto da justiça social, significa exatamente essa postura crítica, por parte da Igreja Católica, em relação ao capitalismo mundial desregulado e destruidor. Por outras palavras, as instituições religiosas universalistas não apenas não geram os atuais problemas mundiais, de que falei acima, senão que também podem assumir, neste século XXI, uma postura de crítica em relação à modernização cultural-econômica totalizante.
} 
e o individualismo dos estilos de vida impacta sua monopolização da interpretação do credo, sua autoridade verticalizada sobre crentes e não-crentes, bem como o tipo de fundamentação essencialista e naturalizada de caráter totalizante que é veiculada desde a instituição religioso-cultural para todos os contextos e sobre todos os indivíduos, acerca de todos os aspectos da vida individual e social.

Nosso tempo está diferente de há poucas décadas: o pluralismo religiosocultural e o individualismo dos estilos de vida estão bastante consolidados enquanto estrutura sociocultural, jurídico-constitucional, política e normativa, inclusive em termos globais, de modo que qualquer proposta de fundamentação epistemológico-moral, de estruturação institucional e de projeto societal devem partir, inevitavelmente, dessas duas grandes conquistas do mundo contemporâneo, que não apenas não podem ser esquecidas, por aqueles projetos de fundamentação e de estruturação institucional, como devem ser assumidas por eles como condição de seu desenvolvimento e de sua construção. Nenhum projeto epistemológicomoral e nenhuma estruturação institucional podem ignorar ou deixar de lado o pluralismo religioso-cultural e o individualismo dos estilos de vida - essa é a novidade dos nossos tempos, a base de nossa vida cotidiana e o ponto de partida teórico-prático de qualquer paradigma ou fundamentação epistemológico-moral5.

\footnotetext{
${ }^{5}$ Uma última palavra sobre o pluralismo religioso-cultural e o individualismo dos estilos de vida. Considero-os uma verdadeira conquista da evolução cultural ocidental em particular, da evolução humana, se se pode falar assim, em geral. Com efeito, o pluralismo religioso-cultural é resultado do próprio desenvolvimento humano em sua heterogeneidade, em sua liberdade crítico-criativa. Simplesmente, é o ponto de partida fundamental de qualquer fundamentação normativa, mormente daquelas que se pretendem universalistas, favorecendo a desconstrução de qualquer forma de chauvinismo, de racismo e de totalitarismo epistemológico-político, posto que se contrapõe diretamente a uma homogeneização estrita. Quanto ao individualismo dos estilos de vida, considero-o como importante fruto das sociedades modernas, na medida em que ele propicia a possibilidade de secularizarem-se os processos de fundamentação cultural, política e institucional. De fato, neste último ponto, os grandes esforços da modernidade consistem exatamente em colocar o individualismo dos estilos de vida como o bastião normativo a partir do qual os códigos e as práticas socialmente vinculantes efetivamente são construídos e adquirem sentido, de modo que o individualismo serviria de contraponto ao conservadorismo e ao dogmatismo. Entretanto, acredito que o puro e simples individualismo, desligado da vinculação social e do ambiente natural, bem como das responsabilidades normativas que daqui advêm (justiça social, democracia política, igualdade sociocultural, proteção ecológica, etc.), é incapaz de resolver os problemas de integração social e de promoção do ambiente que enfrentamos hoje. De todo modo, utilizo este conceito, no texto, com o objetivo de defender que, com sua consolidação nas sociedades democráticas contemporâneas, há uma forte monopolização de certas práticas, de certos símbolos e de certas formas de vida (principalmente gênero e sexualidade) por parte dos próprios indivíduos, o que torna difícil às instituições religioso-culturais assumirem exclusivamente para si a fundamentação moral deles, que passaram a fazer parte irremediável da vida privada de cada indivíduo.
} 
Em relação a isso, é importante frisar-se que o pluralismo religioso-cultural e o individualismo dos estilos de vida não põem em xeque a tradição exegética e mesmo religioso-cultural no que diz respeito à interpretação e ao fomento dos textos sagrados e das práticas comunitárias calcadas na religião e na cultura guardadas pelas religiões institucionalizadas e universalistas. Como insisti ao longo do texto, é evidente que o pluralismo religioso-cultural e o individualismo dos estilos de vida enfraqueceram a capacidade de as instituições religioso-culturais monopolizarem toda a interpretação do credo e legitimarem todos os comportamentos individuais e sociais a partir daquela monopolização da interpretação. Algumas questões passam a ser basicamente objeto de escolha e de vida individuais, outras passam a ser debatidas e orientadas a partir do pluralismo religioso-cultural, mas, no contexto contemporâneo, a tradição exegética e religioso-cultural das instituições religiosas universalistas ainda mantém seu legítimo direito a também ter voz e vez no que tange tanto à interpretação dos próprios textos quanto no que diz respeito a posicionamentos normativos no âmbito da sociedade de um modo mais geral. O que gostaria de deixar claro é que, quando falamos em tradição exegética e religioso-cultural, não precisamos situá-la como contraposta ao pluralismo e ao individualismo, da mesma forma como, quando falamos em pluralismo religioso-cultural e individualismo dos estilos de vida, não precisamos concebê-los como contrapostos à tradição dogmática ligada à exegese e ao fomento dos textos e das práticas sagrados. Não precisamos partir da ideia de que a tradição nega ou esmaga ou anula o pluralismo religioso-cultural e o individualismo dos estilos de vida, assim como não precisamos partir do argumento de que o pluralismo religioso-cultural e o individualismo dos estilos de vida destroem a tradição religioso-cultural dogmática. $\mathrm{Na}$ verdade, a moderação epistemológico-política leva exatamente à promoção do diálogo e da cooperação entre todos, sem que haja uma desvalorização ou uma negação de qualquer posição religioso-cultural, de qualquer grupo, de qualquer indivíduo - o diálogo e a cooperação entre as diferenças com vistas à resolução dos problemas comuns é a grande exigência de nosso século XXI. 


\section{Considerações finais: o grande desafio religioso de nosso tempo}

Os novos tempos, de pluralismo religioso-cultural e de individualismo dos estilos de vida, representam um verdadeiro desafio epistemológico e político às instituições religiosas, que trabalham exatamente a partir de uma fundamentação essencialista e naturalizada. Esse grande desafio epistemológico e político consiste em trazer o pluralismo e o individualismo como bases normativas da mudança e da reformulação para dentro delas e utilizá-los efetivamente para repensar e alterar sua estrutura interna e sua vinculação sociocultural - até que ponto as religiões institucionalizadas estão dispostas a fazer isso? Até que ponto elas estão dispostas a moderar o tipo de fundamentação essencialista e naturalizada que utilizam e a partir do qual trabalham, reformulando amplamente ou mesmo abandonando certas partes do credo? Até que ponto estão dispostas a enfraquecer sua autoridade interna, abdicando da monopolização estrita da legitimação do credo e compartilhando esse mesmo trabalho de legitimação do credo com crentes e até não-crentes?

Todos esses desafios são colocados pela consolidação do pluralismo religioso-cultural e pelo individualismo dos estilos de vida; Isto é, a diferença irredutível é um fundamento normativo que não pode mais ser enfrentado e racionalizado pelas posições epistemológico-morais metafísicas ou mesmo pósmetafísicas, o que implica na incapacidade tanto das concepções essencialistas e naturalizadas quanto do tipo de fundamentação procedimental próprio do pensamento pós-metafísico em servirem como guarda-chuva normativo do pluralismo, dos contextos particulares, localizados histórico-culturalmente. A diferença irredutível não é um fundamento normativo e um ethos sociocultural que pode ser deslegitimado pelas posições epistemológico-morais essencialistas e naturalizadas, bem como pelas suas promotoras, as instituições religioso-culturais universalistas. Reconhecê-la e tomá-la a sério é o ponto de partida epistemológico e político por excelência de nosso tempo, o verdadeiro ponto de viragem para todas 
as injustiças - e para todo o descaso individual, grupal, institucional - que vemos e vivemos em nosso mundo contemporâneo. Tomando o pluralismo religiosocultural e o individualismo dos estilos de vida como sua base normativa, as instituições religioso-culturais transformar-se-ão em pontas-de-lança na realização de um projeto ético-político e sociocultural emancipatório, inclusivo, protetor e fomentador de todas as diferenças. Ora, não há alternativa para a irredutibilidade das diferenças, para o pluralismo religioso-cultural e o individualismo dos estilos e vida. Eles são nossa maior conquista teórico-prática: mantê-la e fomentá-la ao longo do tempo é o trabalho sempre permanente que nos resta.

\section{REFERÊNCIAS}

$11^{\mathrm{a}}$ GENERAL ASSEMBLY. "Relatio Post Disceptationem" of the General Rapporteur, Card. Péter Erdó. Vatican Press, Vaticano, 13/04/2015. Disponível em:<http://press.vatican.va/content/salastampa/en/bollettino/pubblico/2014/10/13/o75 1/03037.html>. Acesso em: 28/04/2015.

CATROGA, Fernando. Entre Deuses e Césares: Secularização, Laicidade e Religião Civil - Uma Perspectiva Histórica. Coimbra: Edições Almedina, 2006.

COLLINS, John J. A Bíblia Justifica a Violência?. Tradução de Walter Eduardo Lisboa. São Paulo: Paulinas, 2006.

CONCÍLIO ECUMÊNICO VATICANO II. Compêndio Vaticano II: Constituições, Decretos, Declarações. Introdução e Índice Analítico de Frei Boaventura Kloppenburg. Petrópolis: Vozes, 1983.

DANNER, Leno Francisco. Um Fundamento para o Ecumenismo: a Irredutibilidade do Outro, Horizonte, Belo Horizonte, v. 12, n. 33, jan.-mar., p.70-98, 2014.

DUSSEL, Enrique. 1492, o Encobrimento do Outro: a Origem do Mito da Modernidade. Petrópolis: Vozes, 1993.

DUSSEL, Enrique. Ética da Libertação: na Idade da Globalização e da Exclusão. Petrópolis: Vozes, 2000.

FORST, Rainer. Contextos da Justiça: Filosofia Política para além de Liberalismo e Comunitarismo. Tradução de Denilson Luís Werle. São Paulo: Boitempo, 2010.

HABERMAS, Jürgen. A Inclusão do Outro: Estudos de Teoria Política. Tradução de George Sperber e de Paulo Astor Soethe. São Paulo: Loyola, 2002. 
HABERMAS, Jürgen. Pensamento Pós-Metafísico: Estudos Filosóficos. Rio de Janeiro: Tempo Brasileiro, 1990.

HABERMAS, Jürgen. Teoria do Agir Comunicativo: Racionalidade da Ação e Racionalização Social (Vol. I). Tradução de Paulo Astor Soethe. São Paulo: Martins Fontes, 2012.

HONNETH, Axel. Luta por Reconhecimento: a Gramática Moral dos Conflitos Sociais. Tradução de Luiz Repa. São Paulo: Editora 34, 2003.

LYOTARD, Jean-François. La Diferencia. Traducción de Alberto L. Bixio. Barcelona: Editorial Gedisa, 1999.

MARRAMAO, Giacomo. Céu e Terra: Genealogia da Secularização. Tradução de Guilherme Alberto Gomez de Andrade. São Paulo: Editora da UNESP, 1997.

RAWLS, John. Justiça como Equidade: Uma Reformulação. Tradução de Cláudia Berliner. São Paulo: Martins Fontes, 2003.

RAWLS, John. Justiça e Democracia. Tradução de Irene Paternot. São Paulo: Martins Fontes, 2000.

RAWLS, John. O Liberalismo Político. Tradução de Dinah de Abreu Azevedo. Brasília: Instituto Teotônio Vilela; São Paulo: Editora Ática, 2002.

RORTY, Richard. Uma Ética Laica. Tradução de Mirella Traversin Martino. São Paulo: Martins Fontes, 2010.

TODOROV, Tzvetan. A Conquista da América: a questão do outro. São Paulo: Martins Fontes, 1993.

VATTIMO, Gianni. Depois da Cristandade: por um cristianismo não religioso. Tradução de Cynthia Marques. Rio de Janeiro: Editora Record, 2004. 